\title{
ACUMULACIÓN Y REFUNDICIÓN DE PENAS: NOTAS SOBRE LA NECESIDAD DE SUPERAR ESTOS CONCEPTOS*
}

\author{
Andrés DíAz GÓMEZ \\ INVESTIGADOR FPU \\ UNIVERSIDAD DE LA RIOJA
}

SUMARIO: I. Introducción; II. Cuestiones previas: las instituciones jurídicas de referencia. II.I. El sistema de determinación de la pena en el concurso real. II.2. La unidad de ejecución penitenciaria (art. I93.2 RP). III. La tradición de los términos en la legislación. IV. «Acumulación» y «refundición», la eterna confusión. V. La necesidad de superar estos conceptos: una propuesta final. VI. Bibliografía citada.

RESUMEN: En este apunte se pretende poner de relieve el problema de la confusión entre los términos «acumulación» y «refundición» en el mundo jurídico-penal y penitenciario, proponiendo la utilización de otras palabras más adecuadas y expresivas del contenido al que hacen referencia.

PALABRAS ClaVE: acumulación, refundición, concurso real de delitos.

ABSTRACT: The aim of this note is to point up the confusion between the words «acumulación» and «refundición» in the Spanish legal framework, proposing to use other accurate words.

KEYWORDS: cumulative sentences, concurrent sentences, multiple criminal offences.

\section{Introducción}

Tradicionalmente vienen utilizándose en el mundo del Derecho las palabras «acumulación» y «refundición» para referirse a sumas o limitaciones de penas o condenas, con efectos penales y penitenciarios. Tales expresiones gozan hoy sin duda de un fuerte arraigo en la doctrina científica y entre los jueces y tribunales, posiblemente por la sencillez aparente de los términos y la comodidad de su utilización. Sin embargo, también originan importantes problemas de comprensión, no sólo porque su semántica no permite inferir la institución concreta a la que hacen referencia, sino porque su uso no es uniforme ni en la doctrina ni en la jurisprudencia. Así, podrá ocurrir, en no pocas ocasiones, que no sea sencillo averiguar a qué se está refiriendo exactamente el autor o el juez que hace uso de las palabras indicadas.

\footnotetext{
* Este trabajo se ha elaborado en el marco del Programa FPU del Ministerio de Educación, Cultura y Deporte.
} 
Lo que se tratará de hacer aquí es mostrar los trazos básicos de esta problemática, poniendo de manifiesto la confusión existente y las dificultades que encierra el uso de estos términos. Con dos advertencias: en primer lugar no se va a entrar en el análisis de las distintas instituciones de referencia, más allá de una somera descripción inicial; en segundo lugar, tampoco se va a proponer una determinada utilización de «acumulación» o «refundición», tan sólo sugerir, como conclusión final, el recurso a otras voces más expresivas de su contenido, con vista a tratar de superar la confusión existente.

\section{Cuestiones previas: las instituciones jurídicas de referencia}

Con carácter previo a adentrarnos en la problemática que anunciábamos en la introducción, se hace necesario precisar sucintamente las instituciones a las que habitualmente se refieren los términos «acumulación» y «refundición», es decir, las instituciones jurídicas de referencia. Por un lado, a veces se utiliza el término «acumulación» para referirse a la fijación del límite máximo de cumplimiento efectivo artículo 76 del Código Penal-, o más ampliamente, al propio sistema de determinación de la pena en caso de concurso real de delitos. Por otro lado, en ocasiones se hace referencia con el nombre de «refundición» a la institución representada por el artículo i93.2 del Reglamento Penitenciario. Nótese que nos situamos en este segundo caso no en la fase de determinación de la pena o penas derivadas del delito o delitos cometidos, sino en la de ejecución de las mismas. En consecuencia, las figuras de los artículos 73, 75 y 76 del Código Penal son puramente penales, mientras que la institución del artículo i93.2 del Reglamento Penitenciario es de naturaleza penitenciaria. No en vano, la regulación de ambas figuras se realiza en normas muy diferentes -no tanto en lo que respecta a su jerarquía, como en la materia-: Código Penal y Reglamento Penitenciario, respectivamente. En definitiva, como vamos a comprobar, la naturaleza de estas instituciones es radicalmente diferente. Incluso, podríamos añadir, algunos autores han señalado su oposición o la posible contradicción entre ambas ${ }^{\mathrm{I}}$. A continuación presentaremos brevemente el contenido y significado de cada una.

\section{II.I. El sistema de determinación de la pena en el concurso real}

Concretar la institución a la que frecuentemente se refieren los operadores jurídicos con el nombre de «acumulación» exige inicialmente precisar la noción de «concurso real». Lo cierto es que el Código Penal no nos proporciona una definición científica de lo que debe entenderse por «concurso real», por lo que es necesario acudir a la doctrina. No obstante, la mayor parte de los autores se han manifestado en términos muy similares: «cuando una pluralidad de hechos de un mismo sujeto constituye una pluralidad de delitos», «cuando varios hechos, realizados por el mismo sujeto, dan lugar a varios delitos o faltas que son susceptibles de enjuiciamiento conjunto» o «una pluralidad de acciones y una pluralidad de preceptos penales violados» ${ }^{2}$. Así explicado, el concurso real no parece crear excesivos problemas y discusiones en la dogmática penal, al menos no al nivel

\footnotetext{
${ }^{\text {I }}$ Así, MANZANARES SAMANIEGO ha señalado que el cumplimiento sucesivo no es compatible con el principio de individualización científica; aunque, según este autor, el carácter especial de la Ley Orgánica General Penitenciaria, con igual rango normativo al Código Penal, lleva a la aplicación preferente del segundo (MANZANARES SAMANIEGO, José Luis, «Reflexiones sobre el 'caso Troitiño', la 'doctrina Parot' y los vaivenes jurisprudenciales en materia de terrorismo», en Diario La Ley, versión electrónica, $\mathrm{n}^{\circ} 7685$, 20II, págs. 3 y I5). Por ese motivo, algunos autores han criticado que no se haya plasmado el artículo i93.2 del Reglamento Penitenciario en la Ley, por su colisión con el principio de cumplimiento sucesivo de las penas consagrado en el Código Penal (FERNÁNDEZ ARÉVALO, Luis y NISTAL BURÓN, Javier, Manual de derecho penitenciario, Aranzadi, Navarra, 20II, pág. 366).

${ }^{2}$ Respectivamente: MIR PUIG, Santiago, Derecho Penal Parte General, Reppertor, Barcelona, 2006, pág. 644; GONZÁLEZ RUS, Juan José, «Artículos 73 y 75 al 78», en COBO DEL ROSAL, Manuel (dir.), Comentarios al Código Penal, Edersa, Madrid, I999, pág. 949; QUINTERO OLIVARES, Gonzalo, Manual de derecho penal Parte general, Aranzadi, Cizur Menor, 2002, pág. 752.
} 
de las demás tipologías concursales. El problema será, pues, la decisión del castigo a imponer. Nuestro Legislador regula sus consecuencias en los artículos 73,75 y 76 del Código Penal. De conformidad con el artículo 73 del Código Penal español, «al responsable de dos o más delitos o faltas se le impondrán todas las penas correspondientes a las diversas infracciones para su cumplimiento simultáneo, si fuera posible, por la naturaleza y efectos de las mismas». Pero no siempre es posible el cumplimiento simultáneo 3 . Por ese motivo, en el caso de que no fuera posible el cumplimiento simultáneo, el artículo 75 del Código Penal ofrece una solución alternativa: el cumplimiento sucesivo de las penas. Señala el mencionado precepto que «cuando todas o algunas de las penas correspondientes a las diversas infracciones no puedan ser cumplidas simultáneamente por el condenado, se seguirá el orden de su respectiva gravedad para su cumplimiento sucesivo, en cuanto sea posible». La respuesta parece, por tanto, sencilla. Sin embargo, no deben pasarse por alto los inconvenientes que tendría este sistema si no es limitado de algún modo, pues las penas no pueden encadenarse sucesivamente hasta la eternidad ${ }^{4}$. Se hace, pues, imprescindible, la existencia de lo que se ha denominado «factores de corrección» ${ }^{5}$. Estos factores están representados por el artículo 76 del Código Penal, que señala que: «el máximo de cumplimiento efectivo de la condena del culpable no podrá exceder del triple del tiempo por el que se le imponga la más grave de las penas en que haya incurrido, declarando extinguidas las que procedan desde que las ya impuestas cubran dicho máximo, que no podrá exceder de 20 años»-excepcionalmente 25, $30040-$.

Una vez examinado sintéticamente el horizonte normativo en el que se enmarca la llamada «acumulación», corresponde ahora tratar de desentrañar qué se entiende habitualmente por este término. Así, la doctrina, en su práctica totalidad, denomina al sistema elegido por el Legislador español para regular las consecuencias del concurso real de delitos como «acumulación», ya sea en su vertiente material o aritmética o en la jurídica. Es decir, el cumplimiento simultáneo o sucesivo de las penas -artículos 73 y $75 \mathrm{CP}-$, según los casos, se denomina «acumulación material»; mientras que con el término «acumulación jurídica» se pretende describir la operación consistente en limitar el cumplimiento sucesivo de las penas -artículo $76 \mathrm{CP}^{6}$. Sin embargo, como veremos posteriormente, en la práctica

\footnotetext{
${ }^{3}$ Como regla, el cumplimiento simultáneo es posible «cuando las penas no se vacían de contenido al cumplirse al mismo tiempo» (MUÑOZ CONDE, Francisco y GARCÍA ARÁN, Mercedes, Derecho penal. Parte general, Tirant lo Blanch, Valencia, 20Io, pág. 538). Sobre esta cuestión, vid. ampliamente GONZÁLEZ RUS, Juan José, «Artículos 73 y 75 al 78 » cit., pág. 952 ss.

4 Vid. v.g., GONZÁLEZ RUS, que examina algunos de los inconvenientes que evita la existencia de lo que llamamos «máximum de cumplimiento» (GONZÅLEZ RUS, Juan José, «Artículos 73 y 75 al 78 , cit., págs. 992 y 993); también GONZÁLEZ CUSSAC, que resume los tradicionales argumentos doctrinales en esta línea (GONZÁLEZ CUSSAC, José Luis, «Comentario al artículo 76», en VIVES ANTÓN, Tomás Salvador, (coord.), Comentarios del Código Penal de 1995, vol. I, Tirant lo Blanch, Valencia, I996, pág. 430). Al fin y al cabo, como señalan MUÑOZ CONDE y GARCÍA ARÁN, la vida de los seres humanos es limitada en el tiempo y es imposible la exacta compensación de los delitos cometidos mediante penas (MUÑOZ CONDE, Francisco y GARCÍA ARÁN, Mercedes, Derecho penal. Parte general, cit., pág. 549). El sistema del cumplimento sucesivo de las penas debe, por tanto, ser limitado de algún modo.

5 En palabras de BOLDOVA PASAMAR (BOLDOVA PASAMAR, Miguel Ángel, «Aplicación y determinación de la pena», en GRACIA MARTÍN, Luis (coord.), Las consecuencias jurídicas del delito en el nuevo código penal español: el sistema de penas, medidas de seguridad, consecuencias accesorias y responsabilidad civil derivada del delito, Tirant lo Blanch, Valencia, I996, págs. 219 y 220).

${ }^{6}$ Así, MUÑOZ CONDE, Francisco y GARCÍA ARÁN, Mercedes, Derecho penal Parte general, cit., págs. 545 y 546; QUINTERO OLIVARES, Gonzalo, Manual de derecho penal Parte general, cit. págs. 753 y 753; MAQUEDA ABREU, María Luisa, «El concurso de delitos», en ZUGALDÍA ESPINAR, José Miguel (dir.), Derecho penal Parte general, Tirant lo Blanch, Valencia, 2002, pág. 892; SUÁREZ-MIRA RODRÍGUEZ, Carlos (coord.), Manual de Derecho penal, tomo I, Thomson Civitas, Cizur Menor, 2004, págs. 403 ss.; CONDE-PUMPIDO FERREIRO, Manuel, «Art. 76», en CONDE-PUMPIDO FERREIRO, Manuel (dir.), Código penal comentado: con concordancias y jurisprudencia, Bosch, Barcelona, 2004, págs. 285 ss.; MIR PUIG, Santiago, Derecho Penal Parte General, cit. pág. 645; SUÁREZ GONZÁLEZ, Carlos, «Artículo 76», en RODRÍGUEZ MOURULLO, Gonzalo (dir.), Comentarios al Código Penal, Civitas, Madrid, I997, pág. 267; GONZÁLEZ RUS, Juan José, «Artículos 73 y 75 al 78», cit., págs. 95I ss.; entre otros. De igual modo, la jurisprudencia viene utilizando habitualmente esta terminología, distinguiendo entre «acumulación material» y «acumulación jurídica» (v.g. SSTS 4 de julio de
} 
resulta muy frecuente la utilización del vocablo «acumulación», sin otros apelativos, para referirse a la operación jurídica del artículo 76 CP. Por este motivo se ha venido a identificar comúnmente «acumulación» con la institución de la limitación del máximo de cumplimiento de la condena.

\section{II.2. La unidad de ejecución penitenciaria (art. I93.2 RP)}

Como adelantábamos al inicio del epígrafe, en este segundo caso nos hallamos en un segundo momento procesal muy distinto del primero, donde la problemática girará en torno a la forma de ejecución de las penas. Precisamente, el artículo 72.I de la Ley Orgánica General Penitenciaria aborda esta cuestión al señalar que «las penas privativas de libertad se ejecutarán según el sistema de individualización científica, separado en grados, el último de los cuales será el de libertad condicional...». El tratamiento penitenciario tiene, pues, una importancia de primer orden, que fuerza a que éste se realice atendiendo a la totalidad de las penas a que haya podido ser condenado el sujeto7. Por este motivo, el artículo i93.2 del Reglamento Penitenciario señala que «cuando el penado sufra dos o más condenas de privación de libertad, la suma de las mismas será considerada como una sola condena a efectos de aplicación de la libertad condicional». Lo que quiere decir que, a la hora de valorar la concesión de la libertad condicional, que generalmente se somete al cumplimiento por el penado de determinados porcentajes de condena, todas las penas deben conformarse en una unidad punitiva -«refundirse», según algunos autores- de manera que se posibilite la aplicación de este último grado de tratamiento penitenciario. Todo ello sin perjuicio de que el principio de unidad de ejecución penitenciaria no se limite a la aplicación de la libertad condicional, puesto que, como ha señalado MANZANARES SAMANIEGO, este principio constituye «requisito indispensable para el tratamiento, pues sería absurdo clasificar y tratar al reo atendiendo a sus responsabilidades penales por separado» ${ }^{8}$.

Dicho esto, la operación del artículo I93.2 del Reglamento Penitenciario, de la que se desprende el principio de unidad de ejecución penitenciaria, ha sido frecuentemente denominada como «refundición», especialmente por la doctrina penitenciarista9.

2000; I7 de junio de 2005; 23 de mayo de 2006; i2 de diciembre de 2008; i8 de febrero de 2008; 29 de enero de 2009; I6 de marzo de 20I0; 2 de febrero de 20I2).

${ }^{7}$ Como indica la STS 29 de septiembre de I992 (FJ. I) «...el tratamiento penitenciario se inspira en la conveniencia o necesidad de, operar, no sobre penas individualizadas, sino sobre la totalidad de las sentencias o condenas pendientes de ejecución, reduciéndolas a una unidad de cumplimiento». Del mismo modo, la STS 24 de junio de I994 (FJ. 3) señala que «...la llamada «unidad de ejecución», en cuanto al tratamiento penitenciario, inspirado en las Reglas Mínimas de Estrasburgo y en la conveniencia de operar, no sobre penas individualizadas, sino sobre la totalidad de las impuestas en las sentencias o condenas pendientes de ejecución, reduciéndolas a una «unidad de cumplimiento» (artículos 66 y 72 de la Ley Orgánica General Penitenciaria); debiendo girar dicha «individualización científica» (como se conoce), sobre el binomio «personalidad criminalduración de la pena»». De este modo, puede afirmarse con CUERDA RIEZU que «no existe una correlación entre el tratamiento y la pena impuesta como consecuencia de un concreto hecho delictivo, sino que la correlación se produce entre el tratamiento y la concreta persona del penado» (CUERDA RIEZU, Antonio Rafael, «El concurso real y la acumulación de penas en la sentencia del Tribunal Supremo I97/2006, de 28 de febrero, relativa al caso Henri Parot: observaciones legales y constitucionales», en Cuadernos de derecho judicial, $\mathrm{n}^{\circ} .7,2006$, pág. 263).

${ }^{8}$ MANZANARES SAMANIEGO, José Luis, «Apuntes de urgencia sobre la sentencia del Tribunal Supremo en relación con el denominado caso Parot», en Diario La Ley, n 6443, 2006, pág. I327.

9 Así v.g. FERNÁNDEZ-PINÓS, José Ernesto, «Acumulación de condenas y refundición de penas», en Estudios jurídicos. Cuerpo de Secretarios Judiciales, $\mathrm{n}^{\circ}$ 2, 2000, págs. 222 y 223; FERNÁNDEZ ARÉVALO, Luis y NISTAL BURÓN, Javier, Manual de derecho penitenciario, cit., pág. 366; ARMENTA GONZÁLEZPALENZUELA, Francisco Javier y RODRÍGUEZ RAMÍREZ, Vicente, Reglamento penitenciario comentado: análisis sistemático y recopilación de legislación, Mad, Alcalá de Guadaíra, 2004, pág. 333; CERVELLÓ DONDERIS, Vicenta, Derecho penitenciario, Valencia, Tirant lo Blanch, 2006, pág. 25I. Vid. también nota al pie nº I3. 


\section{La tradición de los términos en la legislación}

Anteriormente, a la hora de describir las instituciones jurídicas a las que doctrina y jurisprudencia se refieren con términos «acumulación»y «refundición», se han citado los preceptos correspondientes de la normativa vigente, de manera que se ha podido observar que ni Código Penal ni el Reglamento Penitenciario utilizan estas expresiones. Tampoco lo hacen otros preceptos vigentes distintos de los señalados. Pero lo cierto es que, como pretendemos demostrar, no sólo la normativa actual no se refiere a estos términos, sino que tampoco lo hace la legislación histórica. A continuación se procederá a examinar muy brevemente la legislación derogada, prestando especial atención a la figura de la limitación del máximo de cumplimiento.

Puede decirse que ninguno de los Códigos Penales ya derogados ha utilizado los términos «acumulación» o «refundición» para referirse a estas instituciones. No obstante, esta afirmación tiene una excepción: el Código Penal de i822. Esta norma, en su artículo II3, señalaba que «si por un delito mereciere la pena de trabajos perpetuos, y otras más leves por los demás, todas se refundirán en la primera, escepto las pecuniarias, las cuales se impondrán también al mismo tiempo» - sic- ${ }^{10}$. Obsérvese que el precepto habla de «refundición», para referirse, según creemos, a lo que hoy en día se entiende mayoritariamente por «acumulación». Esto es, la limitación de la pena total a la establecida por los trabajos perpetuos, quedando las demás de menos gravedad extinguidas o refundidas en la anterior. En este sentido, se pone de manifiesto la dificultad de comprensión del término, ya que la expresión «se refundirán» guarda más relación con la actual figura del artículo 76 CP que con el i93.2 RP. La copiosa regulación de los artículos II3 y iI4 del Código Penal de I822, que establecía el modo de actuar en caso de concurrencia concursal de penas de diversa naturaleza y entidad, fue abandonada de forma definitiva en el Código Penal de I848. Éste, como el Código de i850, eludió hacer referencia al mecanismo jurídico de la limitación del cumplimiento en prisión. Hubo que esperar al Código Penal de I870 para encontrar el origen y antecedente del actual artículo 76 CP. Señalaba así el artículo $89.2^{a}$ que «sin embargo de lo dispuesto en la regla anterior, el máximum de duración de la condena del culpable no podrá exceder del triple de tiempo por que se le impusiere la más grave de las penas en que haya incurrido, dejando de imponérsele las que procedan, desde que las ya impuestas cubrieren el máximum del tiempo predicho. En ningún caso podrá dicho máximum exceder de cuarenta años». Se trata, pues, de la figura que hemos designado como «acumulación»-o «acumulación jurídica»-, aunque no existe la utilización de tal término en el Código de i87o. La siguiente Ley penal, de I928, reitera en su artículo I63. $^{\mathrm{a}}$ la limitación de la norma precedente, añadiendo que «...por tanto, el Tribunal sentenciador dejará de imponer, aunque declare al reo responsable de mayor número de infracciones, todas las penas procedentes en cuando excedan del triplo expresado». Esta precisión fue de nuevo eliminada en el Código Penal de I932, conteniéndose en el artículo $74.2^{\mathrm{a}}$ una redacción muy similar a la de I870. La redacción originaria del Código Penal de I870 pasaría luego al Código de I944 -artículo $70.2^{a}-$, con algunas alteraciones en las expresiones utilizadas que no afectan al contenido de nuestra exposición. Posteriormente, el Código penal de I973 -artículo 70.2ª - recogería esta redacción, y más tarde, con alguna pequeña modificación, el Código actualmente vigente. En lo que respecta a la normativa penitenciaria, si observamos los Reglamentos más inmediatos en el tiempo, en sus preceptos coincidentes con el actual artículo I93, llegaremos a la misma conclusión. En efecto, el artículo 59 del Reglamento de i98I coincide prácticamente en los mismos términos con el actual texto. Lo mismo sucede con el artículo 56 del Reglamento del Servicio de Prisiones de ${ }_{1956 .}$

Io LÓPEZ BARJA DE QUIROGA, Jacobo, RODRÍGUEZ RAMOS, Luis y RUIZ DE GORDEJUELA LÓPEZ, Lourdes, Códigos penales españoles: Recopilación y concordancias, Akal, D.L., Madrid, I987, pág. 37. La redacción completa de éste y los demás preceptos históricos mencionados puede encontrarse en la misma obra. 
En definitiva, y como conclusión, puede afirmarse respecto de ambos términos que no proceden sino de la doctrina y de la jurisprudencia, pues, tradicionalmente, la norma se ha limitado a enunciar una realidad jurídica que luego ha sido recogida por los intérpretes y designada por éstos a efectos puramente explicativos o demostrativos.

\section{IV. «Acumulación» $\mathrm{y}$ «refundición», la eterna confusión}

En las líneas superiores se ha venido señalando que habitualmente «acumulación» y «refundición» se identifican con instituciones jurídicas diferentes; también se ha indicado que se trata de términos que no proceden de la legislación. Así, aunque estas palabras no sean especialmente reveladoras de las instituciones de referencia, en realidad recurrir a uno $\mathrm{u}$ otro término para identificar cada figura no sería un problema si existiese acuerdo en su utilización. Pero, como veremos a continuación, no existe tal acuerdo. Precisamente, el principal inconveniente es que gran parte de la doctrina y jurisprudencia, $u$ otros operadores del Derecho, utilizan cada palabra con total apatía.

Existe una gran confusión en la doctrina no sobre el contenido y delimitación de las instituciones jurídicas que hemos enunciado, que parece claro, sino sobre la utilización de estos términos para definirlas. Lo cierto es que se evidencian importantes desajustes entre lo que entienden por tales unos y otros autores. Tal es así que un examen de las obras científicas podría llevarnos a distinguir tres grupos diferenciados. Un primer y amplio grupo de autores sería el que utiliza indistintamente el término «refundición» como equivalente a «acumulación», o sea, fundamentalmente, como aplicación de los límites máximos del artículo $76 \mathrm{CP}$. En segundo lugar, otros autores no parecen confundir las diferentes instituciones, utilizando la expresión «acumulación» para el tratamiento de la problemática concursal que se ha mencionado supra. Así, sin aludir a la figura penitenciaria del artículo I93.2 RP, esta sección de la doctrina utiliza estrictamente «acumulación» para referirse a los supuestos de concursos de delitos y de limitación del máximo de cumplimiento, sin incluir el concepto «refundición» como término equivalente ${ }^{12}$. Para finalizar, un tercer bloque estaría caracterizado por aquellos teóricos que distinguen expresamente entre las diferentes palabras, principalmente para reivindicar el uso de «refundición» para el ámbito penitenciario, es decir, en relación con el artículo I93.2 RP ${ }^{\mathrm{I} 3}$. Y

${ }^{\text {II }}$ A título de ejemplo, con independencia del contenido de las obras, pueden citarse los siguientes: MANZANARES SAMANIEGO, José Luis, «Acumulación de penas, individualización científica y aplicación de beneficios penitenciarios (con una referencia especial al "caso Parot')», en BUENO ARÚS, Francisco (coord.), Derecho penal y criminología como fundamento de la política criminal: estudios en homenaje al profesor Alfonso Serrano Gómez, Dykinson, Madrid, 2006, passim; RODRÍGUEZ RAMOS, Luis (coord.), Código Penal comentado y con jurisprudencia, La Ley, Madrid, 2005, págs. 2I3 y 2I4; LANDECHO VELASCO, Carlos María y MOLINA VÁZQUEZ, Concepción, Derecho penal español: parte general, Tecnos, Madrid, 20Io, pág. 505; MARTÍNEZ ARRIETA, Andrés, «La refundición de penas: una interpretación alternativa», en LÓPEZ BARJA DE QUIROGA, Jacobo y ZUGALDÍA ESPINAR, José Miguel (coords.), Dogmática y ley penal: libro homenaje a Enrique Bacigalupo, Marcial Pons, Madrid, 2004, passim; SERRANO BUTRAGUEÑO, Ignacio, «Art. 76», en SERRANO BUTRAGUEÑO, Ignacio y DEL MORAL GARCÍA, Antonio (coords.), Código penal: comentarios $Y$ jurisprudencia, Comares, Granada, 2002, págs. 893 ss.; ZABALA LÓPEZ-GÓMEZ, Carlos, «La 'nueva' refundición o acumulación de condenas: el olvido lamentable del principio de legalidad», en Cuadernos de política criminal, $\mathrm{n}^{\circ} 89$, 2006, passim; SALCEDO VELASCO, Andrés, «La refundición de condenas: acumulación de penas», en Cuadernos de Derecho Judicial, CGPJ, Madrid, I994, passim.

${ }^{12}$ Entre otros muchos: GONZÁLEZ RUS, Juan José, «Artículos 73 y 75 al 78», cit., págs. 949 ss.; CUERDA RIEZU, Antonio Rafael, «La regulación del concurso de delitos en el anteproyecto de Código Penal de i992», en COBO DEL ROSAL, Manuel, RUIZ VADILLO, Enrique et álii, Política criminal y reforma penal: homenaje a la memoria del prof. Dr. D. Juan del Rosal, EDERSA, Madrid, I993, págs. 303 ss.; CALDERÓN CEREZO, Ángel y CHOCLÁN MONTALVO, José Antonio, Derecho penal, Bosch, Barcelona, 200I, págs. 42I ss.; SUÁREZ GONZÁLEZ, Carlos, «Artículo 76», cit. págs. 267 ss.; MAQUEDA ABREU, María Luisa, «El concurso de delitos», cit., págs. 892 ss.; SUÁREZ-MIRA RODRÍGUEZ, Carlos (coord.), Manual de Derecho penal, cit., págs. 403 Ss.; MUÑ̃Z CONDE, Francisco y GARCÍA ARÁN, Mercedes, Derecho penal Parte general, cit., págs. 545 ss.

${ }^{13}$ Además de los que señalaremos a continuación, podemos citar los siguientes: TÉLLEZ AGUILERA, Abel, Jurisprudencia Penitenciaria 1984-1995, Ministerio del Interior, Madrid, I996, págs. I7 y I8; SUANZES PÉREZ, Fernando, «La ejecución de las penas privativas de libertad de adultos y de las medidas privativas de libertad de 
es que no son pocos los autores que, advirtiendo la confusión derivada de la utilización de estas palabras, proponen la utilización de «acumulación -jurídica- de condenas» como límite de cumplimiento de la pena -artículo $76 \mathrm{CP}-\mathrm{y}$ «refundición de condenas» en el ámbito de la unidad de ejecución penitenciaria -artículo I93.2 RP- ${ }^{\mathrm{I} 4}$. Otros autores optan por denominaciones más atípicas. Así, COLMENAR LAUNES distingue a priori entre «acumulación jurídica de penas» y «refundición jurídica de penas», por un lado; y por otro «acumulación de penas», «refundición de condenas» y «refundición material» $\mathrm{o}$ «refundición penitenciaria» ${ }^{15}$. FERNÁNDEZ ARÉVALO parece diferenciar los términos «refundición material», en referencia al artículo I93.2 RP, y «refundición jurídica», como equivalente a la determinación del máximo de cumplimiento ${ }^{16}$. ESPINA RAMOS distingue entre «acumulación jurídica de penas», regulada según él en el artículo 76 del Código Penal, y «acumulación material» o «refundición de condenas», términos que se identificarían con la figura de suma de penas penitenciaria ${ }^{\mathrm{I7}}$. Posteriormente, el autor añadiría la expresión «refundición material» como sinónimo de «refundición de condenas», distinguiéndolo de «acumulación jurídica» ${ }^{18}$. Esta identificación tan compleja también parece ser la opinión mayoritaria de los Jueces de Vigilancia Penitenciaria, que reconducen las expresiones «acumulación material de condenas» y «refundición» al artículo I93.2 del Reglamento penitenciario, diferenciándolas de «acumulación jurídica de condenas» artículo $76 \mathrm{CP}-{ }^{19}$. Por $\mathrm{su}$ parte, Instituciones Penitenciarias viene distinguiendo expresamente ente ambas expresiones, de manera que la «refundición» de las condenas lo es a efectos penitenciarios de aplicación de la libertad condicional, mientras que «acumulación» se identifica con el mencionado artículo 76 del Código Penal ${ }^{2 \circ}$. Respecto al Ministerio Fiscal, éste no muestra a juzgar por sus Circulares y Consultas una postura firme. Así, en algunas ocasiones parece utilizar el término «refundición» en relación con el principio de unidad de ejecución penitenciaria ${ }^{21}$. En otras, sin embargo, creemos que asimila el vocablo a la aplicación del artículo 76 del Código Penal ${ }^{22}$.

los menores: la refundición de condenas (artículo I93-2ª del RP); la acumulación jurídica y los límites de cumplimiento de las penas privativas de libertad de adultos. Acumulaciones y límites de cumplimiento de las medidas privativas de libertad de los menores», en Estudios jurídicos. Ministerio Fiscal, $\mathrm{n}^{\circ}$ 4, 2003, pág. 20; LÓPEZ CERRADA, Víctor Manuel, «La acumulación jurídica de penas», en Revista de Estudios penitenciarios, $\mathrm{n}^{\circ}$ 250, 2004, págs. I3 y 67; GARCÍA ALBERO, Ramón, «Cumplimiento y ejecución de las penas privativas de libertad. El acceso al tercer grado», en GARCÍA ALBERO, Ramón y TAMARIT SUMALLA, Josep-María, La reforma de la ejecución penal, Tirant lo Blanch, Valencia, 2004, pág. 58; FERNÁNDEZ APARICIO, Juan Manuel, Derecho Penitenciario: comentarios prácticos, Sepin, Las Rozas, 2007, pág. 65; CERVELLÓ DONDERIS, Vicenta, Derecho penitenciario, cit., pág. 25I, nota al pie $\mathrm{n}^{\circ} 2$.

${ }^{14} \mathrm{Vid}$. nota al pie anterior.

${ }^{15}$ Cfr. COLMENAR LAUNES, Ángel, «La determinación de la pena en la fase de ejecución penitenciaria», en Revista de Estudios penitenciarios, $\mathrm{n}^{\circ}$ 256, 20I2, pág.I8. A pesar de todo, en las páginas I8 ss. parece el autor confundir los términos de su propia diferenciación.

${ }^{16}$ FERNÁNDEZ ARÉVALO, Luis, «Ejecución de las medidas de seguridad», en Estudios jurídicos. Ministerio Fiscal, n 4, 2003, pág. I07.

${ }^{17}$ Cfr. ESPINA RAMOS, Jorge Ángel, «La prisión perpetua en la España actual», en Actualidad penal, versión electrónica, $\mathrm{n}^{\circ}$ 9, 2002 , pág. 2.

${ }^{18}$ Cfr. ESPINA RAMOS, Jorge Ángel, «La acumulación jurídica de penas: algunas notas prácticas», en Revista de derecho y proceso penal, $\mathrm{n}^{\circ} \mathrm{I} 2,2004$, pág. $\mathrm{I} 4$

I9 Vid. Criterios de actuación, conclusiones y acuerdos aprobados por los Jueces de Vigilancia Penitenciaria en sus XVIII Reuniones, 2009. Criterios 2, 7 у IO.

${ }^{20}$ Así, Instrucción I/2005, de 2I de febrero de 2005, de la Dirección General de Instituciones Penitenciarias (ahora Secretaría General).

${ }^{21}$ Cfr. Consulta I/1998, 3I de marzo de I998, sobre la ejecución continua del arresto de fines de semana. págs. 6 ss.; Circular $\mathrm{I} / 2003,7$ de abril de 2003 , sobre procedimiento para el enjuiciamiento rápido e inmediato de determinados delitos y faltas y de modificación del procedimiento abreviado, pág. 46.

${ }_{22}$ Cfr. Consulta 3/1989, de I2 de mayo, sobre órgano judicial competente para fijar el límite de cumplimiento a las penas privativas de libertad impuestas por delitos conexos enjuiciados en distintos procesos, passim; Circular I/1996, 23 de febrero de 1996, sobre el régimen transitorio del Código Penal de I995, pág. 2I; 
Con todo, probablemente la más importante fuente de desconcierto tenga su origen en la utilización despreocupada de los términos por parte de los órganos judiciales. Efectivamente, como indica SUANZES PÉREZ, la confusión se ha visto incrementada por la terminología de las resoluciones de los tribunales que suelen utilizar el vocablo «refundición» para referirse a la limitación de la duración de las penas al artículo $76 \mathrm{CP}^{23}$. Vamos a prestar atención a la postura de nuestro Tribunal Supremo, acaso reveladora, como órgano jurisdiccional superior. El examen de sus resoluciones evidencia que, lejos de contribuir a unificar y aclarar los problemas terminológicos, nuestro Alto Tribunal no ha hecho sino introducir aún más desconcierto en lo que respecta a los vocablos correctos para denominar las instituciones de referencia; y no digamos nada en relación con los órganos jurisdiccionales inferiores, dada su heterogeneidad. Examinando, pues, la jurisprudencia del Tribunal Supremo, puede llegarse a una conclusión clara: en la práctica totalidad de la de las ocasiones el Tribunal entiende que «acumulación» y «refundición» son la misma cosa, es decir, que ambas expresiones se refieren a la fijación del máximo tiempo de cumplimiento de conformidad con el artículo 76 del Código Penal ${ }^{24}$. Hasta aquí podría pensarse que, por tanto, la postura del Tribunal Supremo es la utilización indistinta de los términos. Sin embargo, hay que señalar alguna excepción muy remarcable. Ya la STS de 5 de septiembre de 2005 distinguió expresamente entre «acumulación jurídica» reconduciéndola a los artículos 988 de la LECrim. y 76 del Código Penal-y «refundición de condenas», entendiendo esta última como «la suma aritmética de las mismas, conforme a lo preceptuado en el art. I93.2 del Reglamento Penitenciario». Poco después, al año siguiente, el Alto Tribunal emitiría una resolución mucho más relevante, la STS 28 de febrero de 2006. Esta sentencia, aparte de alumbrar la conocida «Doctrina Parot», determina categóricamente en el fundamento de derecho cuarto que no debe utilizarse la expresión «refundición» para aludir a la fijación del límite máximo de cumplimiento actual artículo 76 del Código Penal-. Dice la sentencia, exactamente, que: «Es, por ello, que el término a veces empleado, llamando a esta operación una «refundición de condenas», sea enormemente equívoco e inapropiado. Aquí nada se refunde para compendiar todo en uno, sino para limitar el cumplimiento de varias penas hasta un máximo resultante de tal operación jurídica». Sin embargo, la proscripción de la utilización del término «refundición» en referencia a esta institución no terminaría de calar en la doctrina jurisdiccional, ni siquiera en el propio Tribunal Supremo. Puede así observarse que, con posterioridad a la resolución, el Alto Tribunal continuaría en la misma línea que la anterior; es decir, utilizando «refundición»y «acumulación» de forma indistinta ${ }^{25}$.

Tras esta breve exposición en relación con la utilización de las palabras que analizamos, puede concluirse, con NISTAL BURÓN, que «...los términos acumulación y refundición se usan de forma confusa por la jurisprudencia, por la doctrina y en la propia praxis de la administración penitenciaria - a lo que unos llaman acumulación otros llaman

Circular 2/2004, 22 de diciembre de 2004, sobre aplicación de la reforma del Código Penal operada por Ley Orgánica I5/2003, de 25 de noviembre (primera parte), págs. I8 y I9.

${ }^{23}$ SUANZES PÉREZ, Fernando, «La ejecución de las penas privativas de libertad de adultos y de las medidas privativas de libertad de los menores: la refundición de condenas (artículo 193-2 ${ }^{a}$ del RP); la acumulación jurídica y los límites de cumplimiento de las penas privativas de libertad de adultos. Acumulaciones y límites de cumplimiento de las medidas privativas de libertad de los menores», cit., pág. 20.

${ }^{24}$ Sirvan de ejemplo, entre otras muchas, las SSTS 8 de marzo de I994, I5 de julio de 1996, 9 de diciembre de I998, I8 de octubre de 2000, I4 de febrero de 200I, I5 de julio de 2002, 24 de febrero de 2003, 5 de noviembre de 2004 y 30 de junio de 2005 , así como las citadas en la nota al pie siguiente.

${ }_{25}^{25}$ Por ejemplo, SSTS I2 de septiembre de 2006 , io de octubre de 2006,8 octubre de 2007 , I7 de diciembre de 2007,29 de septiembre de 2008 , I de octubre de 2008, I7 de junio 2009, I9 de noviembre de 2009,4 febrero de 20IO, 29 de mayo de 20IO, 2 de febrero de 20 II, 28 de marzo de 20 II, 3 de febrero de 2012 y 6 de marzo de 20I2. Se llegaría incluso al despropósito de utilizar con naturalidad el término «refundición» y simultáneamente indicar en la misma resolución que «el término a veces empleado, llamando a esta operación una «refundición de condenas», sea enormemente equívoco e inapropiado» (v.g. SSTS 28 de marzo de 20II, 2I de octubre de 20II, 8 de marzo de 20I2, 28 de mayo de 20I2). 
refundición - lo que genera no pocas dificultades interpretativas, dado que se trata de instituciones de naturaleza completamente distinta ${ }^{26}$.

\section{La necesidad de superar estos conceptos: una propuesta final}

Resta, para concluir, analizar el sentido gramatical de las palabras que venimos señalando. De este modo comprobaremos que los conceptos «acumulación» y «refundición» no permiten esclarecer per se el contenido de las figuras jurídicas a que se refieren. Su utilización, incluso en el sentido más ampliamente aceptado, introduce confusión. En primer lugar porque los términos no son suficientemente descriptivos de su contenido. En efecto, ambos parecen significar la misma cosa o cosas parecidas, y se presenta complicado que el lego en Derecho, o incluso el jurista que no tenga un conocimiento aproximado de su contenido y de la confusión terminológica, sea capaz de intuir las diferencias entre ambas a la vista de su denominación. Aún más, la identidad de las expresiones con su significado jurídico dista mucho de ser certera, pues perfectamente podría emplearse «acumulación» para referirse a la institución de la «refundición», y viceversa; lo cual sin duda justifica que frecuentemente se hayan utilizado indistintamente, como hemos señalado con anterioridad.

Veamos, pues, qué se entiende por «acumulación»y «refundición» desde una perspectiva gramatical. No hace falta decir que, como sucede cotidianamente con otros términos o instituciones del mundo del Derecho, las expresiones comunes no tienen por qué coincidir con las jurídicas y que los diccionarios tampoco tienen por qué hacer referencia a las mismas. Sin embargo, creemos que un análisis desde esta perspectiva será sumamente revelador. De acuerdo con el Diccionario de la Lengua Española de la RAE, «acumular» es «juntar sin orden gran número de cosas» o bien «reunir una cantidad notable de algo» ${ }^{27}$. Si comparamos estas definiciones con la que tomamos del uso mayoritario en sede jurídica de «acumulación»-artículo $76 \mathrm{CP}-$, no obtenemos coincidencia, pues al fin y al cabo el artículo 76 del Código Penal, también usualmente denominado «acumulación jurídica», no es sino la fijación del límite máximo de cumplimiento efectivo de la condena ${ }^{28}$. Sin embargo, si entendemos este término de forma más amplia, en el sentido de la suma aritmética de las penas a efectos del cálculo de la condena total en el concurso real de delitos -artículo $75 \mathrm{CP}-$, no hay duda de que el ajuste de «acumular» es mucho más preciso. Es decir, resulta mucho más correcto, semánticamente hablando, utilizar «acumulación» como la llamada «acumulación material» del artículo $75 \mathrm{CP}$, a efectos de sumar las penas para su cumplimiento sucesivo artículo $75 \mathrm{CP}-$, que utilizar el término a efectos del artículo $76 \mathrm{CP}^{29}$. Y ello a pesar de que,

${ }^{26}$ NISTAL BURÓN, Javier, «El cumplimiento de las condenas no susceptibles de acumulación jurídica. Problemática y soluciones posibles», en Diario La Ley, versión electrónica, n 6964, 2008, nota final nº 7 .

${ }^{27}$ De conformidad con la $23^{\mathrm{a}}$ edición del DRAE. De acuerdo con la $22^{\mathrm{a}}$ edición del DRAE, sin embargo, puede entenderse por «acumular» «juntar y amontonar», una definición similar pero que quizás es más clarificadora en el sentido de «sumar» penas (vid. www.rae.es).

${ }^{28}$ En este punto, debe advertirse que el sentido último del término «acumulación» o «acumulación jurídica» dependerá del significado que se otorgue a la operación que se enuncia en el artículo 76 del Código Penal. Esto es importante, porque hasta la STS 28 de febrero de 2006 existía un relativo acuerdo en la doctrina en que la determinación del máximum de cumplimiento generaba una nueva pena. Así, el surgimiento de una nueva y única pena derivada la extinción de las impuestas tradicionalmente se ha vinculado a «refundición»; no en vano gramaticalmente posiblemente tenga más sentido que el otro término. Hoy, sin embargo, parece que la mayor parte de la doctrina, a la vista del Código Penal actual y tras la interpretación del Tribunal Supremo contenida en su sentencia de 28 de febrero de 2006 , apuesta por la pervivencia de todas las penas impuestas cumpliéndose sucesivamente hasta alcanzar el límite correspondiente. Esta última idea parece ajustarse mejor a «acumulación», como sumar o juntar varias penas.

${ }^{29}$ Así, LÓPEZ CERRADA, que respecto a la denominada «acumulación jurídica» (artículo $76 \mathrm{CP}$ ) señala se adaptaría mejor al término «refundir» (LÓPEZ CERRADA, Víctor Manuel, «La acumulación jurídica de penas», cit., pág. I5). También ESPINA RAMOS, Jorge Ángel, «La acumulación jurídica de penas: algunas notas prácticas», cit., pág. I4. 
como se ha descrito supra, «acumulación material» y «acumulación jurídica» no sean sino las dos modalidades de una misma figura -«acumulación»- que ha servido para denominar la regulación de las consecuencias del concurso real de delitos. En este sentido el DRAE nos ofrece una acepción más de esta palabra, esta vez proveniente del Derecho: «unir unos procedimientos a otros para que sean resueltos por una sola sentencia o resolución». Esta significación de «acumular» parece aludir a las reglas de «acumulación de objetos procesales» propios de los supuestos de conexidad del artículo I7 LECrim. Es decir, conforme al artículo 300 LECrim., cada delito es objeto, en principio, de un sumario y un proceso distinto; sin embargo, tratándose de los delitos a que se refiere el mencionado artículo I7 LECrim., todos estos ilícitos se juzgan en el mismo proceso. Nada indica esta acepción del DRAE, por tanto, acerca de la operación del artículo 76 CP. Además, nótese que la coincidencia entre conexidad y limitación del cumplimiento efectivo de la condena no es total, puesto que como señala el artículo 76.2 CP, también puede aplicarse en determinados supuestos aunque las penas se hayan impuesto en distintos procesos.

Con respecto a la expresión «refundición», «refundir» no es sino, en las acepciones del término más relacionadas, «volver a fundir» o «comprender» o «contener». En nuestra opinión, a pesar de que no pocos autores apuestan por la utilización del término, no parece claro que con la aplicación del artículo I93.2 RP se «refunda» realmente algo: sólo se suman las penas para considerarlas -ficticiamente- como una sola, con los efectos ya indicados. Algo parecido ocurriría con el artículo $76 \mathrm{CP}$ y la figura conocida frecuentemente como «acumulación jurídica», aunque en este caso la solución podría ser distinta dependiendo de la interpretación jurídica del precepto ${ }^{30}$. En todo caso, parece que en ninguna de las instituciones las penas han estado antes unidas, como para necesitar que sean vueltas a fundir o a unir. Incluso aunque se entendiera que de la operación de establecimiento de un límite máximo de cumplimiento -artículo $76 \mathrm{CP}$ - surge una nueva pena independiente, extinguiéndose las impuestas en el proceso, el término refundición encaja mal. Tal vez tendría más sentido la palabra «fundición» 0 «fusión»

Ha quedado expuesto, pues, que nos encontramos ante dos palabras de origen doctrinal, y que, como tales, no encuentran reflejo léxico en la norma. Así, ni el Código Penal, ni las leyes procesales, como tampoco las leyes penitenciarias, utilizan realmente estos términos, sino que se limitan, con mayor o menor precisión, a describir sus efectos y consecuencias. Por ese motivo, más allá de los problemas interpretativos intrínsecos de ambas instituciones, en el ámbito estrictamente funcional, encontramos notables inconvenientes conceptuales. Como ha sido advertido ya por algunos autores, ha existido -y sigue existiendo- una considerable confusión entre ambas figuras. Tengan o no claro los operadores jurídicos y los académicos el contenido de ambas instituciones, ha sido frecuente la utilización despreocupada de los términos «acumulación» y «refundición», cuyo uso indistinto no ha logrado sino incrementar el desconcierto en la materia. Como se ha tratado de exponer, se trata de una confusión a la que ha contribuido no sólo la doctrina, sino también los órganos jurisdiccionales. Lo paradójico es que, a pesar los problemas que supone utilizar los términos «acumulación» y «refundición», los autores que se ha referido directamente a este problema, apuestan por dotar de un apelativo definido a las figuras a las que nos venimos refiriendo -generalmente «acumulación» para el supuesto contemplado en el artículo $76 \mathrm{CP}$ y «refundición» para lo dispuesto en el artículo I93.2 CP-, pero no por prescindir del uso de ambas denominaciones ${ }^{32}$. LÓPEZ CERRADA, probablemente el autor que más tiempo ha dedicado al análisis de las instituciones desde la perspectiva gramatical, afirma así que «desde el punto de vista gramatical no se puede establecer una diferencia

$3^{\circ}$ Vid. nota al pie $n^{\circ} 28$.

${ }^{31}$ Como señala, según dice LÓPEZ CERRADA, DE LAMO RUBIO (Cfr. DE LAMO RUBIO, Jaime, Penas $y$ Medidas de Seguridad en el Nuevo Código, Bosch, Barcelona, I997, pág. 3I2, citado en LÓPEZ CERRADA, Víctor Manuel, «La acumulación jurídica de penas», cit., pág. I5).

${ }^{2}$ Vid. nota al pie $\mathrm{n}^{\circ} \mathrm{I} 3$. 
clara y determinante», aunque según el mencionado autor los términos «ofrecen un acoplamiento razonablemente lógico» ${ }^{33}$. NISTAL BURÓN afirma que deben usarse estos términos «independientemente del significado etimológico de ambas expresiones» ${ }^{34}$. No creemos que deba ser así, pues estaríamos ignorando la razón de la existencia de las palabras, su significación, por razones de «tradición» que no se alcanzan a comprender. Por eso, y como conclusión final a estas notas sobre los términos «acumulación» y «refundición» de penas, no se va a proponer la utilización de una u otra palabra para referirse a una $u$ otra institución. Esto sólo serviría para añadir una pizca más de ruido al embrollo ya existente, respecto de unos términos que en realidad no terminan de ajustarse apropiadamente con ninguna de las figuras referidas. Por eso, posiblemente la mejor solución sea prescindir de ambas expresiones para denominar las instituciones de referencia, ya sea utilizando los preceptos correspondientes -artículo 76 CP o artículo I93.2 $\mathrm{RP}-\mathrm{u}$ otras denominaciones alternativas. Entre estas alternativas, en relación con el primer precepto, podría encontrarse «limite máximo de cumplimiento» o, utilizando la terminología del antiguo artículo $70.2^{\mathrm{a}}$ del Código Penal de I973, «máximum de cumplimiento». También, de forma más precisa, haciendo uso de las palabras exactas del artículo $76 \mathrm{CP}$, «máximo de cumplimiento efectivo de condena». Respeto a la institución correspondiente al Reglamento Penitenciario, podría utilizarse «suma aritmética de las penas a efectos de aplicación de la libertad condicional», «suma unitaria de penas para ejecución penitenciaria» o «unidad punitiva penitenciaria», por ejemplo. Obviamente, no se trata de un elenco cerrado, pues las posibilidades y alternativas son cuantiosas. Lo que interesa destacar es que las denominaciones propuestas, y otras que se nos pudieran ocurrir, son compatibles entre sí, incluso simultáneamente, y además son más expresivas de su contenido que las tradicionales expresiones «acumulación» y «refundición», contribuyendo a superar la ya antigua confusión entre ambas.

\section{Bibliografía citada}

ARMENTA GONZÁLEZ-PALENZUELA, Francisco Javier y RODRÍGUEZ RAMÍREZ, Vicente, Reglamento penitenciario comentado: análisis sistemático y recopilación de legislación, Mad, Alcalá de Guadaíra, 2004.

BOLDOVA PASAMAR, Miguel Ángel, «Aplicación y determinación de la pena», en GRACIA MARTÍN, Luis (coord.), Las consecuencias jurídicas del delito en el nuevo código penal español: el sistema de penas, medidas de seguridad, consecuencias accesorias y responsabilidad civil derivada del delito, Tirant lo Blanch, Valencia, 1996.

CALDERÓN CEREZO, Ángel y CHOCLÁN MONTALVO, José Antonio, Derecho penal, Bosch, Barcelona, 200 I.

CERVELLÓ DONDERIS, Vicenta, Derecho penitenciario, Valencia, Tirant lo Blanch, 2006.

COLMENAR LAUNES, Ángel, «La determinación de la pena en la fase de ejecución penitenciaria», en Revista de Estudios penitenciarios, $\mathrm{n}^{\circ}$ 256, 2012.

CONDE-PUMPIDO FERREIRO, Manuel, «Art. 76», en CONDE-PUMPIDO FERREIRO, Manuel (dir.), Código penal comentado: con concordancias y jurisprudencia, Bosch, Barcelona, 2004.

CUERDA RIEZU, Antonio Rafael, «La regulación del concurso de delitos en el anteproyecto de Código Penal de I992», en COBO DEL ROSAL, Manuel, RUIZ VADILLO, Enrique et álii, Política criminal y reforma penal: homenaje a la memoria del prof. Dr. D. Juan del Rosal, EDERSA, Madrid, I993.

- «El concurso real y la acumulación de penas en la sentencia del Tribunal Supremo I97/2006, de 28 de febrero, relativa al caso Henri Parot: observaciones legales y constitucionales», en Cuadernos de derecho judicial, $\mathrm{n}^{\circ} .7,2006$.

DE LAMO RUBIO, Jaime, Penas Y Medidas de Seguridad en el Nuevo Código, Bosch, Barcelona, I997.

ESPINA RAMOS, Jorge Ángel, «La prisión perpetua en la España actual», en Actualidad penal, versión electrónica, $n^{\circ}$ 9, 2002 .

- «La acumulación jurídica de penas: algunas notas prácticas», en Revista de derecho y proceso penal, n I2, 2004.

33 LÓPEZ CERRADA, Víctor Manuel, «La acumulación jurídica de penas», cit., pág. I5.

34 NISTAL BURÓN, Javier, «El cumplimiento de las condenas no susceptibles de acumulación jurídica. Problemática y soluciones posibles», cit., nota final $n^{\circ} 7$. 
FERNÁNDEZ APARICIO, Juan Manuel, Derecho Penitenciario: comentarios prácticos, Sepin, Las Rozas, 2007.

FERNÁNDEZ ARÉVALO, Luis, «Ejecución de las medidas de seguridad», en Estudios jurídicos. Ministerio Fiscal, $\mathrm{n}^{\circ} 4,2003$.

FERNÁNDEZ ARÉVALO, Luis y NISTAL BURÓN, Javier, Manual de derecho penitenciario, Aranzadi, Navarra, 2 OII.

FERNÁNDEZ-PINÓS, José Ernesto, «Acumulación de condenas y refundición de penas», en Estudios jurídicos. Cuerpo de Secretarios Judiciales, $\mathrm{n}^{\circ}$ 2, 2000.

GARCÍA ALBERO, Ramón, «Cumplimiento y ejecución de las penas privativas de libertad. El acceso al tercer grado», en GARCÍA ALBERO, Ramón y TAMARIT SUMALLA, Josep-María, La reforma de la ejecución penal, Tirant lo Blanch, Valencia, 2004.

GONZÁLEZ CUSSAC, José Luis, «Comentario al artículo 76», en VIVES ANTÓN, Tomás Salvador, (coord.), Comentarios del Código Penal de 1995, vol. I, Tirant lo Blanch, Valencia, I996.

GONZÁLEZ RUS, Juan José, «Artículos 73 y 75 al 78», en COBO DEL ROSAL, Manuel (dir.), Comentarios al Código Penal, Edersa, Madrid, I999.

LANDECHO VELASCO, Carlos María y MOLINA VÁZQUEZ, Concepción, Derecho penal español: parte general, Tecnos, Madrid, 2010.

LÓPEZ BARJA DE QUIROGA, Jacobo, RODRÍGUEZ RAMOS, Luis y RUIZ DE GORDEJUELA LÓPEZ, Lourdes, Códigos penales españoles: Recopilación y concordancias, Akal, D.L., Madrid, I987.

LÓPEZ CERRADA, Víctor Manuel, «La acumulación jurídica de penas», en Revista de Estudios penitenciarios, $\mathrm{n}^{\circ}$ $250,2004$.

MANZANARES SAMANIEGO, José Luis, «Acumulación de penas, individualización científica y aplicación de beneficios penitenciarios (con una referencia especial al 'caso Parot')», en BUENO ARÚS, Francisco (coord.), Derecho penal y criminología como fundamento de la política criminal: estudios en homenaje al profesor Alfonso Serrano Gómez, Dykinson, Madrid, 2006.

- «Apuntes de urgencia sobre la sentencia del Tribunal Supremo en relación con el denominado caso Parot», en Diario La Ley, $\mathrm{n}^{\circ}$ 6443, 2006.

- «Reflexiones sobre el 'caso Troitiño', la 'doctrina Parot' y los vaivenes jurisprudenciales en materia de terrorismo», en Diario La Ley, versión electrónica, $n^{\circ} 7685$, 2011.

MAQUEDA ABREU, María Luisa, «El concurso de delitos», en ZUGALDÍA ESPINAR, José Miguel (dir.), Derecho penal Parte general, Tirant lo Blanch, Valencia, 2002.

MARTÍNEZ ARRIETA, Andrés, «La refundición de penas: una interpretación alternativa», en LÓPEZ BARJA DE QUIROGA, Jacobo y ZUGALDÍA ESPINAR, José Miguel (coords.), Dogmática y ley penal: libro homenaje a Enrique Bacigalupo, Marcial Pons, Madrid, 2004.

MIR PUIG, Santiago, Derecho Penal Parte General, Reppertor, Barcelona, 2006.

MUÑOZ CONDE, Francisco y GARCÍA ARÁN, Mercedes, Derecho penal. Parte general, Tirant lo Blanch, Valencia, 20I0.

NISTAL BURÓN, Javier, «El cumplimiento de las condenas no susceptibles de acumulación jurídica. Problemática y soluciones posibles», en Diario La Ley, versión electrónica, n 6964, 2008.

QUINTERO OLIVARES, Gonzalo, Manual de derecho penal Parte general, Aranzadi, Cizur Menor, 2002.

RODRÍGUEZ RAMOS, Luis (coord.), Código Penal comentado y con jurisprudencia, La Ley, Madrid, 2005.

SALCEDO VELASCO, Andrés, «La refundición de condenas: acumulación de penas», en Cuadernos de Derecho Judicial, CGPJ, Madrid, I994.

SERRANO BUTRAGUEÑO, Ignacio, «Art. 76», en SERRANO BUTRAGUEÑO, Ignacio y DEL MORAL GARCÍA, Antonio (coords.), Código penal: comentarios y jurisprudencia, Comares, Granada, 2002.

SUANZES PÉREZ, Fernando, «La ejecución de las penas privativas de libertad de adultos y de las medidas privativas de libertad de los menores: la refundición de condenas (artículo I93-2 ${ }^{\mathrm{a}}$ del RP); la acumulación jurídica y los límites de cumplimiento de las penas privativas de libertad de adultos. Acumulaciones y límites de cumplimiento de las medidas privativas de libertad de los menores», en Estudios jurídicos. Ministerio Fiscal, $\mathrm{n}^{\circ}$ 4, 2003.

SUÁREZ GONZÁLEZ, Carlos, «Artículo 76», en RODRÍGUEZ MOURULLO, Gonzalo (dir.), Comentarios al Código Penal, Civitas, Madrid, I997.

SUÁREZ-MIRA RODRÍGUEZ, Carlos (coord.), Manual de Derecho penal, tomo I, Thomson Civitas, Cizur Menor, 2004.

TÉLlEZ AGUILERA, Abel, Jurisprudencia Penitenciaria 1984-1995, Ministerio del Interior, Madrid, I996. 
ZABALA LÓPEZ-GÓMEZ, Carlos, «La ‘nueva' refundición o acumulación de condenas: el olvido lamentable del principio de legalidad», en Cuadernos de política criminal, $n^{\circ} 89,2006$. 